\title{
Climate Forcing During the Holocene
}

\author{
Raymond S. BRADLEY
}

Climate System Research Center, Department of Geosciences, University of Massachusetts, Amherst, USA; rbradley@geo.umass.edu

What caused Holocene climate variations? On the very longest, multi-millennial timescales, the main factors affecting Holocene climate change are related to orbital forcing (changes in obliquity, precession and eccentricity). Decadalto century-scale changes may be related to solar forcing (changes in total solar irradiance) and changes on shorter timescales (decadal to inter-annual) are most likely related to volcanic forcing (Bradley, 2003). Not all climatic variability seen in the Holocene can be ascribed to specific external forcings. For example, the $\sim 8200$ calendar year BP "event", seen in many paleoclimatic archives, resulted from catastrophic pro-glacial lake drainage at the margins of the Laurentide Ice Sheet (Alley et al., 1997; Barber et al., 1999). This rapid flooding of the North Atlantic with freshwater had a significant regional climate impact, unrelated to any external forcing. Internal modes of climate system variability (e.g. El Niño-Southern Oscillation, North Atlantic Oscillation, Pacific Decadal Oscillation) that probably vary on both long and short timescales - though we know relatively little about their long-term behavior-may also produce significant changes in regional climate. And stochastic resonance in the climate system - by which a weak quasi-periodic forcing signal may be amplified into a non-linear, bi-stable climate signal-may have brought about relatively abrupt changes in the past by pushing the system across critical thresholds (Ruzmaikin, 1999). Thus, the spectrum of Holocene climate variability reflects the combined effects of all of these forcings and feedbacks within the climate system.

Orbital forcing involves a significant redistribution of energy, both seasonally and latitudinally (Fig. 1). In the early Holocene, precessional changes led to perihelion at the time of the northern hemisphere summer solstice (whereas today, it is closer to the winter solstice).

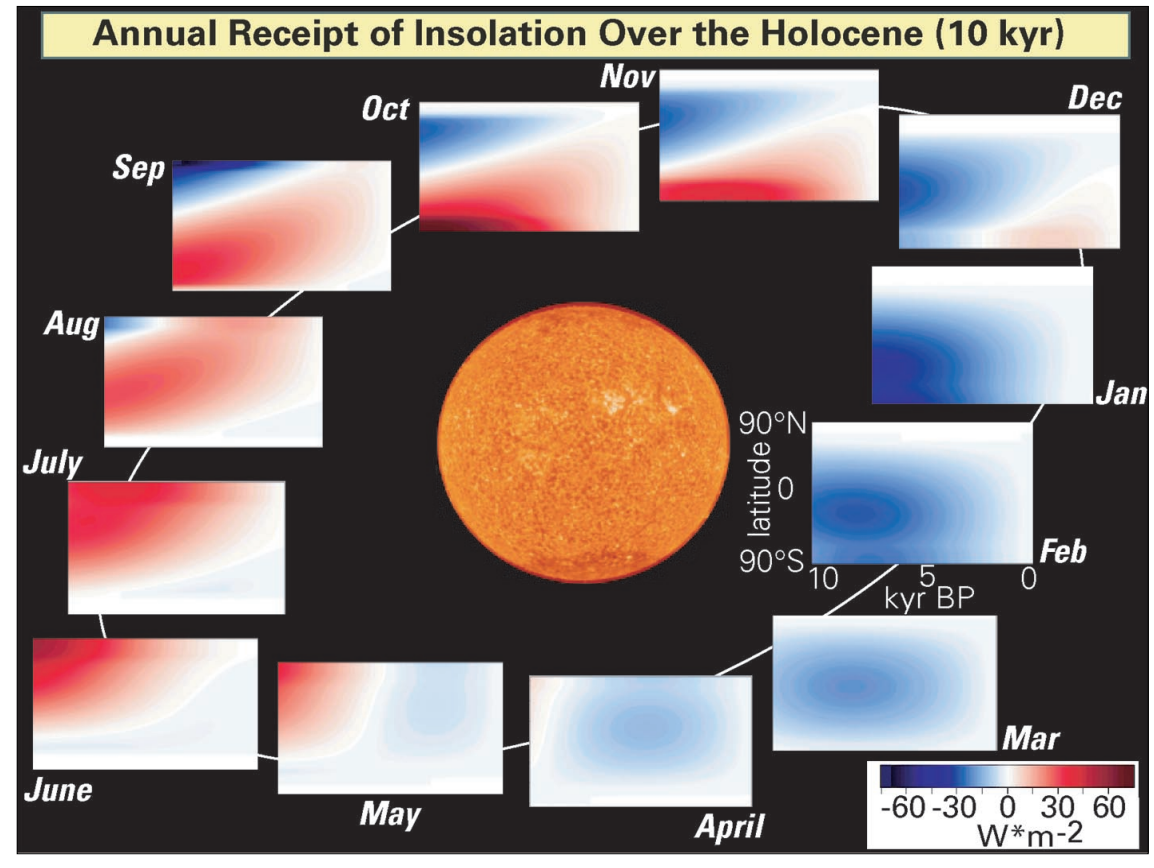

Figure 1: Schematic representation of insolation anomalies at the top of the atmosphere relative to 1950 levels. Anomalies are color-coded in $W^{-2}$. The x-axis of each monthly panel shows changes from 10,000 calendar years BP (left) to today (right). The $y$-axis shows latitude from $90^{\circ} \mathrm{N}$ (top) to $90^{\circ} \mathrm{S}$ (bottom) (figure prepared by Anne Waple).

This resulted in higher summer insolation in the early Holocene at all latitudes of the northern hemisphere (ranging from $\sim 40 \mathrm{~W} \mathrm{\textrm {m } ^ { - 2 }}$ higher than today at $60^{\circ} \mathrm{N}$ to $25 \mathrm{~W}$ $\mathrm{m}^{-2}$ higher at the Equator). Thus, July insolation (radiation at the top of, or outside, the atmosphere) has slowly decreased over the last 12,000 years (Fig. 1). Anomalies during southern hemisphere summers were smaller, centered at lower latitudes, and were opposite in sign (that is, insolation increased over the course of the Holocene). For example, January insolation anomalies at $20^{\circ} \mathrm{S}$ were $\sim 30 \mathrm{~W} \mathrm{\textrm {m } ^ { - 2 }}$ below current values in the early Holocene.

Changes in solar irradiance (energy emitted by the Sun) might be expected to affect all parts of the Earth equally. However, this is not so because the response to solar irradiance forcing is amplified regionally, as a result of feedbacks and interactions within the atmosphere (Rind, 2002). The record of solar variability in the Holocene is discussed further in the accompanying article by Goslar. Here, I would only note that there are many
Holocene paleoclimatic studies that claim solar forcing has driven observed changes, based largely on comparisons of proxy records with the ${ }^{14} \mathrm{C}$ anomaly series. It remains to be seen how robust these relationships are, and what plausible mechanism might link solar activity/irradiance variations with climate in widely separated parts of the globe, from the Arabian Sea and Africa, to the North Atlantic and Greenland. One possibility (seen in some model simulations) involves solar variations influencing the Hadley circulation (intensity and/or extent), which then leads to tropical and sub-tropical precipitation anomalies, and to further teleconnections to extra-tropical regions.

It is well known, from studies of instrumental records, that explosive volcanic eruptions can have short-term cooling effects on overall hemispheric or global mean temperatures (Robock, 2000). This results from direct radiative effects, with the volcanic aerosol reducing energy receipts at the surface, plus associated circulation changes that may result from such effects. Most temperature effects are not detect- 


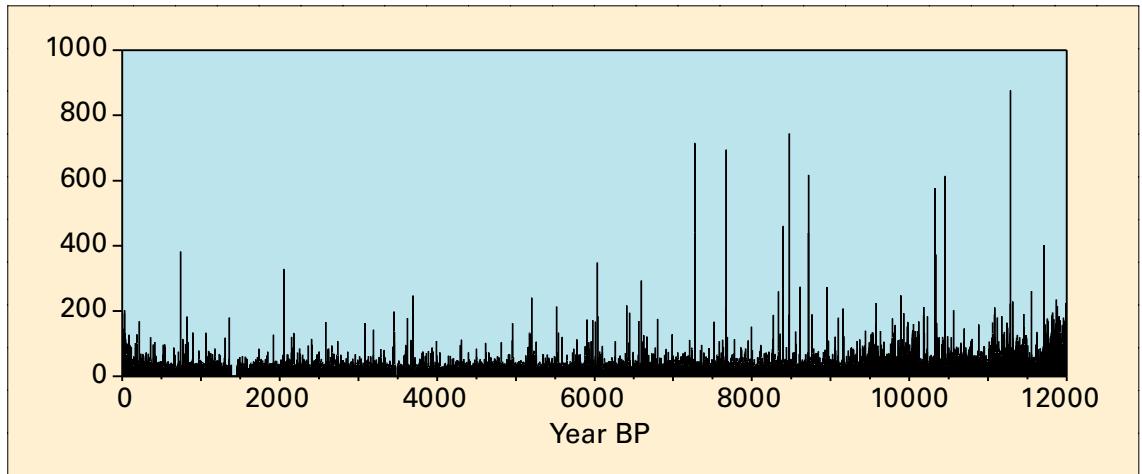

Figure 2: Holocene record of volcanic sulfate (anomalies from background variations) recorded in the GISP2 ice core from Summit, Greenland (Zielinski et al., 1994).

able after a few years, so individual explosive eruptions only contribute short-term variability to the spectrum of Holocene climate. However, if eruptions were more frequent in the past, or if they happened to occur in clusters, it is possible that the cumulative effect of eruptions could have persisted for longer, resulting in decadal- to multi-decadal scale impacts. Such effects would be enhanced if the initial cooling led to feedbacks within the climate system, such as more persistent snow and sea-ice cover, which would raise the surface albedo and possibly alter the atmospheric circulation. Indeed, the non-seasalt sulfate record from the GISP2 ice core does suggest that there were periods of more frequent explosive eruptions in the past, such as in the period 9500-11500 calendar years BP (Fig. 2) (Zielinski et al., 1994) Furthermore, in the early Holocene there were many large volcanic signals, greater in magnitude than those recorded after the eruption of Tambora (1815), the largest eruption in recent centuries. Of course, a larger sulfate signal might simply mean that the eruption event was closer to the deposition site, so we do not have a definitive long-term record of the magnitude of overall volcanic forcing, or more specifically, of atmospheric optical depth and its distribution latitudinally (cf. Roberston et al., 2001). Energy balance and GCM studies that have parameterized the effects of explosive volcanism and solar forcing over recent centuries suggest that these two factors can explain most of the variability of temperatures over the last millennium (e.g. Crowley, 2000). It therefore seems likely that they have also played a significant role in overall Holocene forcing on inter-annual to century timescales.

\section{RefERENCES}

Alley, R.B., Mayewski, P.A., Sowers, T., Stuiver, M., Taylor K.C. and Clark, P.U., 1997: Holocene climatic instability: a prominent, widespread event $8200 \mathrm{yr}$ ago. Geology 25: 483-486.

Barber, D.C., Dyke, A., Hillaire-Marcel, C., Jennings, A.E., Andrews, J.T., Kerwin, M.W., Bilodeau, G. McNeely, R., Southon, J., Morehead, M.D. and Gagnon, J.M., 1999: Forcing of the cold event of 8,200 years ago by catastrophic drainage of Laurentide lakes. Nature 400: 344-348.

Bradley, R.S., 2003: Climate forcing during the Holocene. In: Global Change in the Holocene: approaches to reconstructing fine-resolution climate change. A.W. Mackay, R.W. Battarbee, H.J.B. Birks \& F. Oldfield (eds.). Arnold, London (in press)

Robock, A., 2000: Volcanic eruptions and climate. Reviews of Geophysics 38: 191-219.

Zielinski, G., Mayewski, P.A., Meeker, L.D., Whitlow, S., Twickler, M.S., Morrison, M., Meese, D.A., Gow A.J. and Alley, R.B., 1994: Record of explosive volcanism since 7000 B.C. from the GISP2 Greenland ice core and implications for the volcano-climate system. Science 264: 948-952.

\title{
Tephra, a Powerful Tool for Precision Dating and Correlation
}

\author{
Jon R. Pilcher ${ }^{1}$, Ray Bradley ${ }^{2}$, Lesleigh Anderson ${ }^{2}$ and Pierre Francus ${ }^{2}$ \\ 1School of Archaeology and Palaeoecology, Queen's University, Belfast, Northern Ireland; j.pilcher@qub.ac.uk \\ ${ }^{2}$ Department of Geography, University of Massachusetts, Amherst, MA, USA; rbradley@geo.umass.edu; land@geo.umass.edu; \\ francus@geo.umass.edu
}

\section{Summary}

Icelandic tephra is proving to be a valuable new chronological and stratigraphical tool for the palaeoenvironmentalist in NW Europe. It is particularly useful in the historic period where radiocarbon dating seldom provides adequate precision, and also in situations where sediments are unsuitable for such dating because of variable marine influence.

\section{Geographical Distribution and Temporal Range}

Tephra is the air-fall component of ejecta from a volcano. Tephras can be found embedded in deposits in many areas of the world, in fact there is probably no part of the globe from which such deposits are absent. The use of Icelandic tephras in stratigraphic studies and as a dating tool is well developed in NW Europe. Tephra particles are usually less than 100 micrometers (commonly 20-60 $\mu$ in diameter) and are glass (Fig. 1). In all the studies described here, the tephra is invisible in the cores and sections and must be detected microscopically. The ideal medium for detection of minute traces far from the parent volcano is a highly organic matrix such as peat. The tephra can be released by burning sub-samples of the organic material and dissolving the peat ash in dilute acid. The

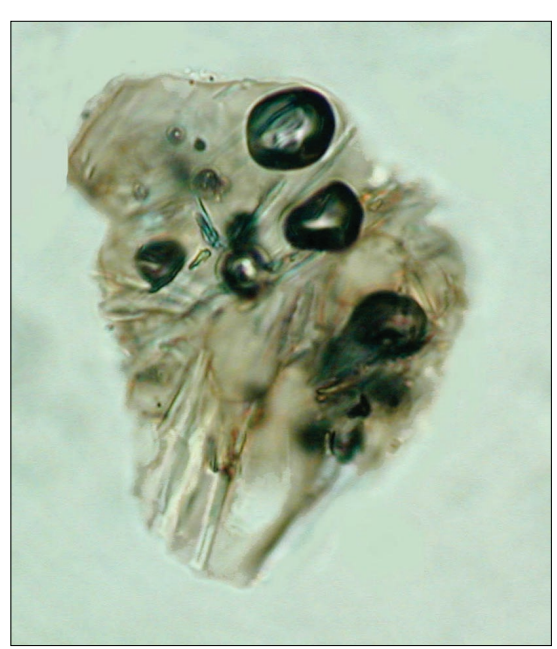

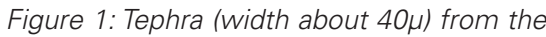
AD 1158 eruption of Hekla found in peat from the Lofoten Islands. 